\title{
Music Streaming, Festivals, and the Eventization of Music
}

\author{
Abstract \\ A key aspect of music-streaming services is the user's access to their vast libraries and \\ abundant choices anytime and anywhere. This article explores how artists performing at a \\ large music festival in Norway were streamed before, during, and after the festival over the \\ course of four different years. The data shows that festival streams grew over 40 percent \\ compared to control weeks and were particularly pronounced among users who lived near \\ the venue. The article then argues that changes in listening patterns may reflect a more \\ general shift towards the "eventization" of streaming media.
}

Keywords: music streaming, music listening, music culture, music festivals, eventization, big data, WiMP Music

\section{Introduction}

The advent of digital music technologies has brought about a new environment for the diffusion and reception of music (Burkart; Jones, "Music and the Internet"; Jones, "Music That Moves"; McCourt and Burkart; Sterne). In recent years, as well, different forms of online services have gained in popularity. In Norway, Spotify is the most-used streaming service, but WiMP Music (now integrated into TIDAL) also holds a large market share. According to TNS Gallup, 52 percent of Norwegian Internet users had access to Spotify by the second quarter of 2015, while 19 percent had access to WiMP Music/TIDAL. By July 2016, TNS Gallup claimed that 74 percent of the online population had access to a music streaming service (that is, of the 96 percent of people with Internet access in Norway), and 54 percent of that population was streaming on a daily or weekly basis. Digital music 
technologies have clearly changed the way people listen to music, as well as the way the music business works and its revenue streams flow. Currently, Norway is the most developed market in terms of music-streaming usage (along with Sweden), and it also has the highest per capita spending on music (Ingham). As Norway has long been regarded as a laboratory for new-media development in general (Karlsen et al.; Sundet), a study of this market's streaming-service use will likely herald potential developments in online music culture elsewhere.

One of the key defining aspects of interactive streaming services such as Spotify and WiMP Music is the access they provide to vast libraries, the contents of which can be retrieved on demand, anytime and anywhere. ${ }^{1}$ This presents listeners with unprecedented possibility and choice regarding what to listen to. Compared to other formats and means of distributing music, streaming sets an extremely low threshold for choosing to listen to something new, given that there is no extra cost or time involved in doing so.

This article takes into account streaming's sheer musical scope and asks, in turn, what impact major musical events might have on everyday streaming practice. It explores this impact using a large musical and media event in Norway, the Øya music festival, and asks the following research questions:

- How does a major cultural event influence the activity in a music-streaming service before, during, and after the event?

- How can we understand and conceptualize the relationship between large events and everyday listening in the context of streaming media?

In recent years there has been a turn in music research toward the role of music in everyday life, and this includes acknowledging the use of music as a way to influence mood, emotions, and physical energy levels (DeNora; Hochschild; North, Hargreaves, and Hargreaves; Sloboda and O’Neill). Tia DeNora demonstrates how many of her informants use music to 
stir strong emotions or remind themselves of certain times, places, and relationships (65). At the same time, music represents a remarkable intersection between the personal, emotional, and intimate, on the one side, and the social, collective, and shared, on the other, as David Hesmondhalgh (2) reminds us.

While DeNora and others provide valuable insight into everyday listening at the individual level, scholars like Hesmondhalgh (40) and Simon Frith (Frith, "Music") call for richer and more detailed descriptions of the social aspects of music in everyday life via collective experiences, community, and communication. Frith describes his hopes for more empirical studies of music in social life:

To my mind, ongoing investigation of people's tastes and the current research focus on issues of identity are much less interesting projects than an ethnography which would try to map in detail people's timetable of engagement, the reasons why particular music gets particular attention at particular moments, and how these moments are, in turn, imbricated in people's social networks. (46, italics added) This pursuit is important, claims Frith, because what people listen to is more important for their sense of themselves than what they watch or read. Patterns of music use provide a better map of social life than viewing or reading habits. Music just matters more than any other medium. (46)

In addition to the aforementioned social implications, detailed empirical insight into the listening patterns of large groups of users might be useful when evaluating broad social theories of modern society and contemporary consumer culture, such as Zygmunt Bauman's metaphors of "solid" and "liquid" modernity. As more media move toward access-based services or "tethered appliances" (Zittrain), the exploration of music streaming - arguably the most mature form of access-based media, in terms of use and diffusion — may also shed light on changes in other fields, media, and media cultures to come. Finally, in a culture where 
music streaming is the dominant technology for music listening, it is productive to look at the ways in which streaming technology influences patterns of use, in terms of affordances (Gibson), phonograph effects (Katz), or material form (Gillespie, Boczkowski, and Foot; Straw).

As more and more forms of media consumption become characterized by abundance rather than scarcity, both in the Nordic countries and elsewhere, aspects of the patterns of use in an all-you-can-eat context are of great interest, including whether and how access to "everything," anytime and anywhere, changes how we listen to and appreciate music, and what kind of music is being produced and how. This study attempts to provide insights into listening patterns related to music streaming, and into the relationship between streaming and live music events, in a way that will contribute to a better understanding of the role of technology in contemporary music listening.

After a brief review of previous research on the relationship between large events and mass media, I will look at the relationship between the Øya music festival and the WiMP Music streaming service, which is the case study for this article. I will also discuss the research material and methods of the Clouds and Concerts project, as well as its results, because findings from the project introduce to the time and location of music streaming in relation to the Øya festival, as well as some of the ways in which music listeners interact with the streaming interface. Lastly, I will address what I term the eventization of music listening, as well as event-based listening on the micro and macro levels, arguing that the "festival effect" on streaming patterns exemplifies a broader trend whereby external events influence streaming patterns on an invidual and a social level. 


\section{Previous Research}

Research into the relationship between large events and mass media reaches back to the 1940s (see, for example, Hadley Cantrill's [1940] study of the panic caused by Orson Welles's radio play The Invasion from Mars or ceremonial events in broadcasting [Couldry, Hepp, and Krotz]). More recently, Daniel Dayan and Elihu Katz's seminal Media Events: The Live Broadcasting of History focuses on historical ceremonial events that attracted large audiences, such as coronations, royal weddings, Olympics, presidential debates, and the moon landing. Dayan and Katz unpack these media events as shared experiences with a communal or ritual role that furthers social solidarity, but they do not record empirical data related to the actual responses of media audiences to the events (Scannell, "Media Events") or account for events that were not televised "live" but instead, perhaps, broadcast over time and/or over an "ensemble of media" (Ytreberg). While there has been a large body of work devoted to such media events since Dayan and Katz's study, there have been relatively few empirical studies of media usage, particularly concerning large events of a less extraordinary and transformative nature, such as an annual music festival.

There is, on the other hand, a growing scholarly interest in festivals that has paralleled their explosion in public popularity over the last twenty years (Gibson and Connell). This festivalization of culture has been discussed by scholars from different traditions, such as cultural studies and cultural policy research (Florida; Häußermann and Siebel; Tjora; Waterman), event studies and event marketing (Getz, Event Studies; Yeoman et al.), cultural economy and sponsorship (Holt; Skinner and Rukavina), event tourism (Getz, Event Management; Getz, "Event Tourism”), brand management (Rowley and Williams), studies of urban and rural development (Duffy; Gibson and Connell), and studies of fans and fandom (Begg; Mackellar). Even though music festivals account for most festivals, the role of music at festivals is still an under-researched area, despite notable exceptions (Brennan and 
Webster; Frith, "Live"; Fonarow). As with media events research, as well, there has been little empirical study of actual media use before, during, and after a large festival.

Before the digital distribution of music, empirical studies of music use by large audience groups were methodologically challenging and hence rare. With P2P sharing and services like Last.fm now tracking the music played by their users, several studies have arisen that explore questions related to music preferences (Schlitter and Falkowski) and homophily and taste (Baym and Ledbetter). A few studies have also used data mining or "big data" approaches in order to explore the network effects of musical taste over time by Last.fm users (Lee and Cunningham); others have explored musical features such as timbre or tempo in databases like the "million song dataset" (Schindler, Mayer, and Rauber) or MyStrands playlist set (Baccigalupo and Plaza). There are also examples of research into the network effects of taste in the music databases (Buldu et al.).

This is the first study to take a "big data" approach to discussing the effect of a large, local event on music-streaming patterns in a limited geographical space and music culture (Norway). Interestingly, a Spotify report (Page) takes a somewhat similar approach in studying the streaming patterns related to sixteen artists at a festival in the Netherlands (see more in the methods section below). Also, Tarleton Gillespie discusses related phenomena, although not from an empirical point of view, discussing trending algorithms in (primarily) social media in a forthcoming article (“\#trendingsistrending”).

\section{The Øya Music Festival and WiMP Music Streaming Service}

The Øya music festival is one of the largest popular music festivals in Norway, presented annually in Oslo since 2000. It takes place over four days during the second week of August and boasts some 16,000 daily visitors at the festival park, as eighty bands perform on four stages. According to organizers, around 85,000 attendees come to the festival (many of 
whom attend several of the festival days, resulting in an estimated 40,000 to 50,000 unique visitors). While it has an indie rock profile, the festival also features genres such as electronica, rap, metal, and soul, performed by a mix of well-established international headliners and local and international acts with disparate followings. Referring to itself as a boutique festival, Øya is oriented toward innovation and quality in a way that reflects an acute awareness of music trends and conventions (Kjus and Danielsen), and it has thus become a destination festival (Fonarow) for fans outside of Norway as well.

Norwegian streaming service WiMP Music was launched to the public in February 2010 with a monthly subscription model that was priced at NOK $99(\$ 10)$; it had 520,000 paying subscribers by the end of 2013. The subscription provides access to a ever-growing library of music that featured around six million tracks at launch and thirty-five million when it was acquired by Shawn "Jay Z" Carter (via Project Panther Ltd) in the first quarter of 2015, then continued under the brand name Tidal. As of July 2016, Tidal (WiMP Music) was reported to be available in forty-six countries with 4.2 million paying subscribers (Roberts).

WiMP Music (and Tidal) features a somewhat different user interface and profile than Spotify, including curated, localized content in each of its markets. ${ }^{2}$ Local editorial teams publish reviews and promote artists, playlists, album releases, and local events in the local language — see Kjus for an account of the editorial processes at WiMP Music and Strutz for a comparison of user interfaces and affordances at WiMP and Spotify. Over the course of this study, WiMP Music published thousands of curated playlists, as well as features and profiles of artists and events. An in-house editorial team curated most of these lists, though notable artists, music journalists, and festival bookers accounted for roughly 10 percent of them as well. ${ }^{3}$ Shortly after the service was introduced in 2010, WiMP Music developed strategic alliances with several local music festivals, which it promoted through playlists and editorial 
campaigns. In the case of the Øya festival, playlists, as well as information about the festival acts, was co-curated by festival organizers and the WiMP editorial team. ${ }^{4}$

\section{Material and Methods}

Researchers interested in studying the details of the everyday use of music across a large population have found little to work with in media technologies like LPs and CDs, which do not track their own use. This forces the researcher to rely on observation or ethnography (as in Fonarow) or on the memory of users' music listening via surveys. Streaming media, however, allow the researcher to observe music behavior indirectly, because all music listening is tracked in detail (with additional metadata such as song title, artist, time stamp, album, track number, genre, and so on), in order to compensate artists, labels, and rights holders, and to help streaming providers improve their services.

The research project Clouds and Concerts: Mediation and Mobility in Contemporary Music Culture at the University of Oslo has gained access to anonymized streaming data from WiMP Music that encompasses all of the streaming activity by all of the users in Norway over a total of seventy-two weeks in 2010,2011,2012, and 2013, respectively, for further analysis. In accordance with a non-disclosure agreement, absolute numbers of users and subscribers were excluded from the study or converted into relative numbers, as this was considered market-sensitive data for WiMP Music, in terms of both its competitors and the stock market. ${ }^{5}$ Due to privacy regulations and ethical guidelines for research in Norway, all of the users were anonymized, and the research project only had access to aggregated demographic data (gender, postal codes, and broad age groups).

The present study was designed to analyze whether and how music streaming is influenced by a large event that users of a streaming service would know about. As mentioned, it is also the first study to take a "big data" approach to discussing the effect of a 
large, local event on music-streaming patterns in a limited geographical space and music culture (Norway). This study is unique in that it builds on data related to all users of a popular streaming service within this music culture. ${ }^{6}$ Some years after the start of the present research, interestingly, Spotify published the results of an internal study of streaming patterns in the Netherlands related to sixteen artists before, during, and after the Lowlands festival there from 15 to 17 August 2014 (Page). ${ }^{7}$ The study found a clear "bounce" in the streaming numbers of sixteen festival artists for the 1,500 Spotify users who attended the festival (8). The Spotify study, however, does not address whether the festival influenced the streaming patterns of users who did not attend the festival. Moreover, the study does not account for all of the two hundred artists who performed there, only a small sampling.

The present study, on the other hand, asks how the streaming audience as a whole relates to a large cultural event, with a particular focus on patterns of streaming before, during, and after the event. This study does not look at how music festivals are constructed as media events or how they function as ritual practices, nor does it look at how the festival audience in particular uses streaming. Instead, it looks at the ways in which a major event may generate and influence media activity and use - in this case, related to contemporary streaming practice.

The Øya music festival, then, was chosen as a case, including all of the streams in Norway by any of the 319 artists who performed at the festival over the course of four consecutive years. The same nine weeks of data logs were reviewed each year, including the seven weeks before, during, and after the event, as well as two control weeks in the springtime - that is, before external media attention started turning to the festival, and before festival-related playlists began to be promoted actively within the service. In addition, a larger sampling of editorial activity and playlist creation from 2012 made it possible to study pre-event activity and listening for several months leading up to the event in that year. The 
data consists of streaming and search logs by all users in Norway, whether they attended the festival or not, as there was no way of knowing where these users were located physically when they streamed their music, apart from the postal code of the home address for about a third of them. Since the aim was to study the influence of the event on general streaming patterns in Norway, it was not necessary to separate the festival attendees from other streamers. Streaming data and search logs were provided by WiMP Music's data warehouse, imported into our own servers and databases, and queried using SQL. ${ }^{8}$ The data analysis of the streaming material was carried out in cooperation with researchers in the Telenor Group and research assistants in the Clouds and Concerts project.

In addition to streaming data, interviews were performed and ongoing conversations were held with key personnel from the Øya festival organization (mainly people responsible for booking and marketing, such as Mandelid, quoted here) and WiMP Music (mainly the editorial team, such as Rindal, quoted here, and various developers and managers of operations) to acquire background information regarding the streaming service, the festival organization, and the ways in which they worked with editorial activities and promotion. The research project was also provided with documents of editorial activities in WiMP (e.g., launch dates and times of banner placement) for further study. In addition, 23 focus-group interviews with a total of 124 users of streaming services were also carried out, as reported elsewhere (Hagen and Lüders; Kjus and Danielsen).

The focus groups addressed a variety of topics (such as the experience of attending live music events, habits regarding streaming services, the role of mobile phone listening, and everyday listening habits). In order to account in detail for the results of the quantitative streaming patterns, this article only touches upon the focus groups in passing to contextualize the quantitative patterns in terms of, for example, user motivations. It is worth noting that the qualitative material and quantitative data from the outset sought to address whether and how 
a major festival influenced listening patterns. Because the streaming data consists of all paying subscribers in Norway, it was well suited to addressing whether and how streaming the artists at a major event such as the Øya festival influenced a large population of music listeners, while the qualitative data was better suited to addressing in depth how a relatively few festival goers experienced this influence, and why they listened to the artists who were performing at the festival. In a different article, Kjus and Danielsen report more fully on the experiences of the festival attendees based on the focus group interviews.

When the focus-group interview guide was developed (by Danielsen, Due, and myself), we did not think to include questions about whether and how major events might influence general listening patterns outside of major festivals. However, as I worked with the quantitative material, I turned to more general event-related patterns as well, which I will address later in this article (and in Maasø and Toldnes). When I then revisited the focusgroup interviews to see whether and how they talked about general event-related patterns in their discussions of general listening patterns (while not being explicitly asked about it), I found some interesting results. Due to the space constraints, only a few examples will be included in the present discussion.

\section{Results}

\section{Spike in Festival Streams}

The main finding of the study involves the clear spike in the streaming of festival artists during the festival week each year, compared to weeks before and after, or what one might call a "festival effect" (figure 1). 


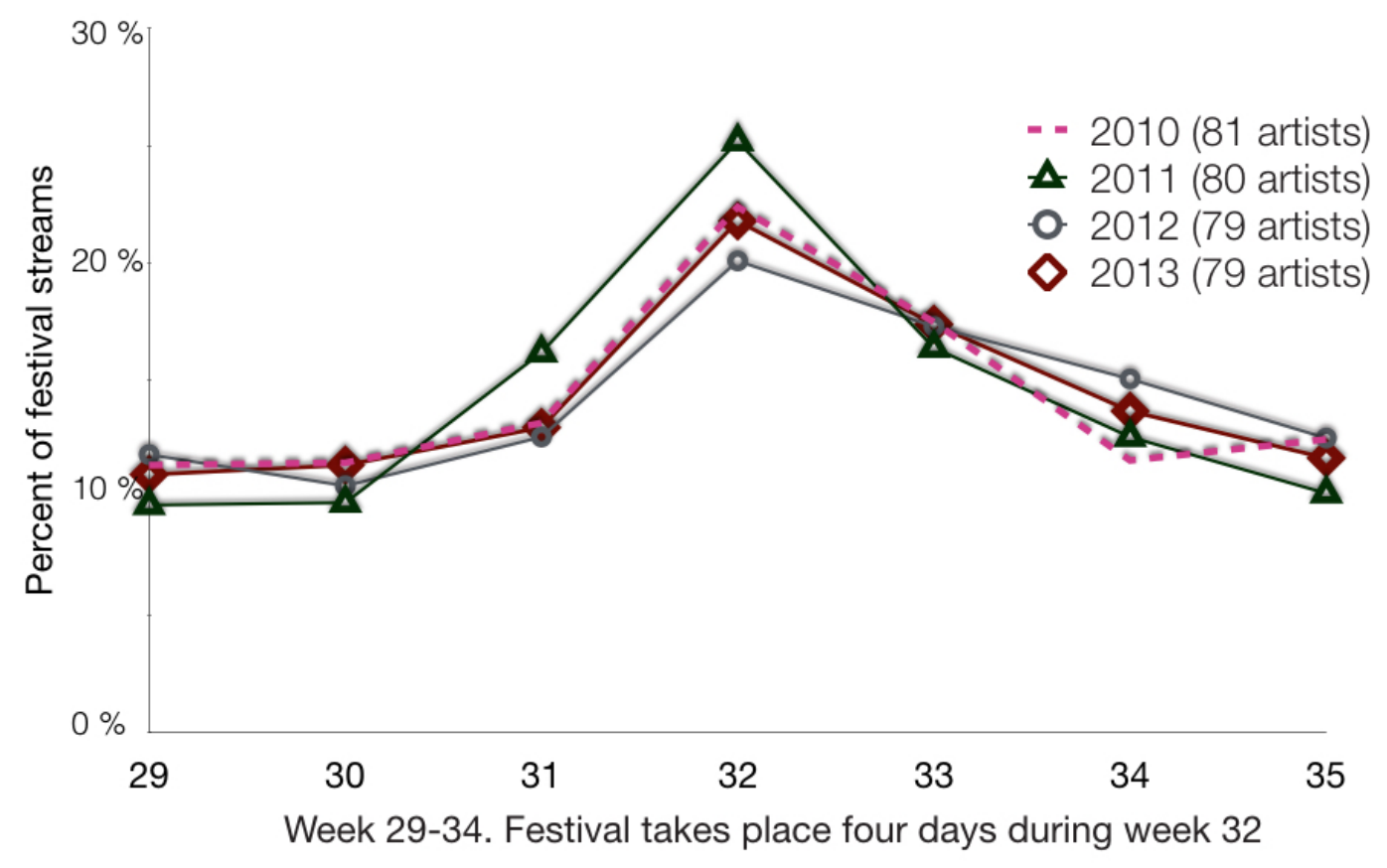

Figure 1: Relative distribution of all streams of festival artists over seven weeks before, during and after the Øya festival, 2010 to 2013. Streams of all festival artists over seven weeks add up to $100 \%$ in each year.

As figure 1 shows, the main streaming pattern appears in all four years of the study. Within the seven-week "festival period," there is a sharp rise of 106 percent on average over the four years in question between the first week in the period (week 29) and the peak during week 32, when the artists are playing live at Øya. While the streaming of festival artists drops off fairly quickly after the festival in each year, the level during week 35 , three weeks after the festival took place, remains 7 percent higher on average than week 29, three weeks before the festival took place. 
Importantly, the overall level of festival streaming during the "festival period" was considerably higher than it was during the two control weeks. The average during the sevenweek period (the mean of weekly means) was 43 percent higher than the average during the two control weeks in early summer, before the festival buzz had started to take effect. This indicates that pre- and post-listening patterns influence streaming several weeks before and after the festival event itself.

\section{Location}

While there was no way of knowing the extent of the potential overlap between the streaming audience and the festival audience for the four years in question, it was possible to study the location (that is, the postal codes of subscribers) of the streaming audience in relation to the festival venue for two of the years. As figure 2 shows, it is clear that the share of festival streams increases with one's proximity to the venue. While all subscribers have the same peak in streaming of festival artists, the share of festival streams by registered subscribers living within a ten-kilometer radius of the venue was almost twice that of subscribers living between fifty and one hundred kilometers from the venue.

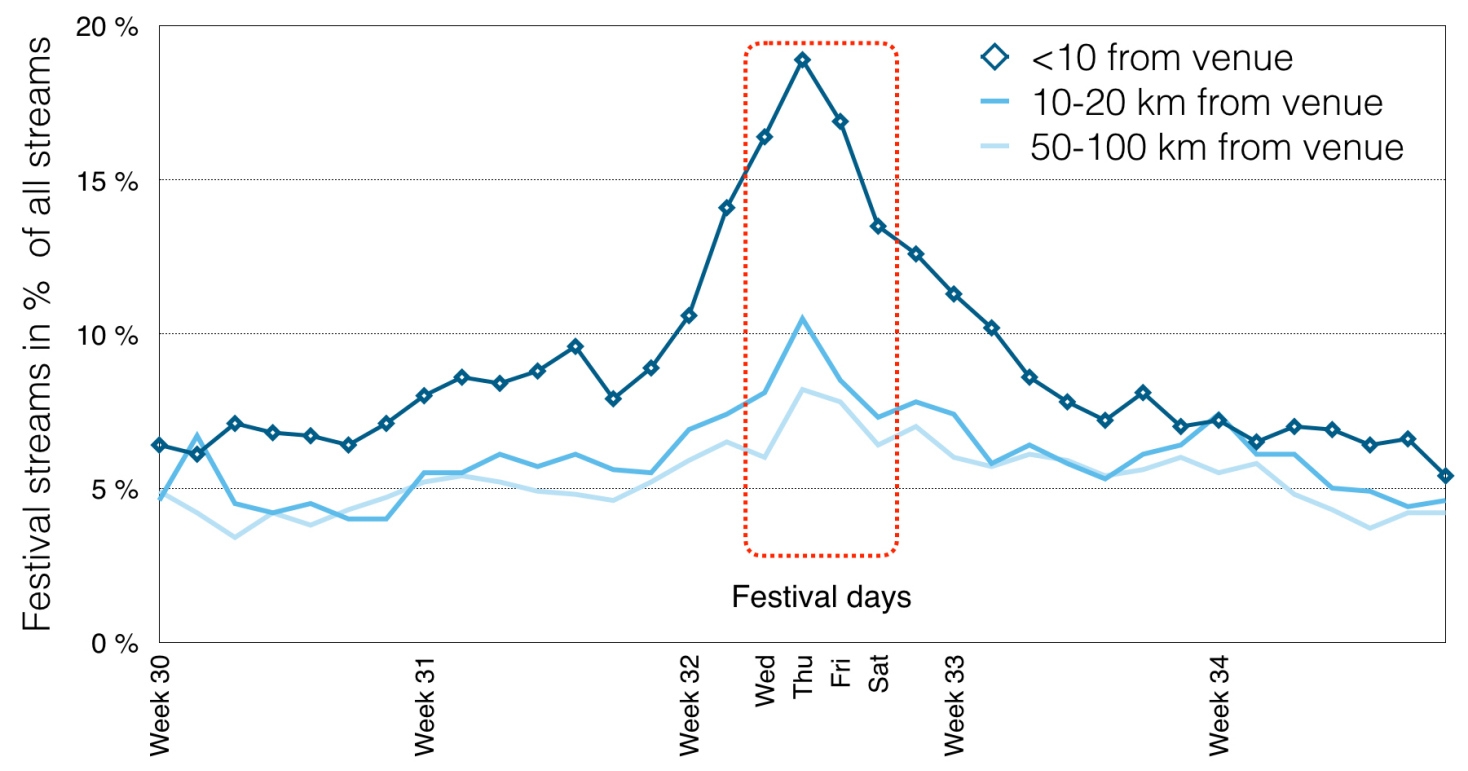


Figure 2: The streaming of festival artists as a percentage of all streaming before, during and after the Øya music festival in 2011 and 2012 (over the course of five weeks in total), mapped to the distance of the subscribers' registered postal address from the venue. Most of Oslo falls within the under-ten-kilometer radius, while all of Oslo and parts of the suburbs are within a twenty-kilometer radius. Close to half of the population of Norway lives in southeastern Norway, within one hundred kilometres or a couple of hours' drive from Oslo.

During the four festival days, there were, on average, 21.1 percent more festival streams by users living within a ten-kilometer radius of the venue than there were festival streams by users in the suburbs that were ten to twenty kilometers away, and 131 percent more festival streams by users in the city (less than ten kilometers from the venue) than there were festival streams by users living between fifty and one hundred kilometers away.

It is likely that this effect of distance reflects both an actual circumstance- those who live close to the festival tend to attend it — and a vicarious one - those nearby who did not go would still have been very aware of it, especially during the actual festival days, and perhaps wanted to check out what was happening via streaming.

While one cannot stipulate the exact overlap between streaming users and festival audience during the four years in question, it is safe to assume that there was a larger overlap in 2010 than in the following years. This is because streaming users exceeded the number of possible festival attendees many times over, and because the demographic data for later years indicate that users became more mainstream in their tastes as the user base grew, and thus overlapped less with the indie/alternative profile of the festival. ${ }^{9}$ 


\section{User-Generated Playlists and Editorial Activity}

One interesting question to explore concerns the influence of editorially promoted content within the music service in the weeks leading up to the festival, in relation to activity initiated by the users themselves. Because the richness and granularity of the data provided by WiMP Music improved significantly later in the research period, particularly concerning the use of playlists and editorial content, the following discussion will be restricted to the role of these playlists in 2012.

Because of the way playlist streams were registered in the data warehouse of WiMP Music at the time our data gathering in 2013, it was not possible to tell the origin of playlist streams - that is, whether they came from editorial or user-generated playlists. For example, a user could have copied all or part of an editorial list, making it appear to be a user-generated list. One way to work around this limitation was to study the creation dates of what appeared to be user-generated lists containing festival artists (that is, which contained a name consisting of one or more festival keywords, such as Øya, Øyafestivalen, Oyafestival, and so on), then compare those lists to the different editorial activities related to the festival.

Figure 3 shows the creation of user-generated lists containing the same artists and songs as those promoted through editorial activity in the WiMP Music player in 2012, as well as dates for that editorial activity. The high correlation between peaks in playlists and editorial activity indicates that many users indeed copied the editorial playlists or created their own based on those released by WiMP Music in cooperation with the festival. As the figure shows, many festival playlists were also created at times that did not correspond to any editorial events, and the frequency of user-generated playlist creation increased during the final weeks leading up to the festival, which corresponded to the increase in festival prelistening. 
Of all playlists containing a festival artist for the seven-week "festival period" from 2012, the five editorial festival playlists accounted for 88 percent of all playlist streams that included festival artists, while user-generated playlists accounted for a mere 12 percent of playlist streams (including 3 percent of streams involving lists which were identical to, and hence likely copies of, the editorial lists).

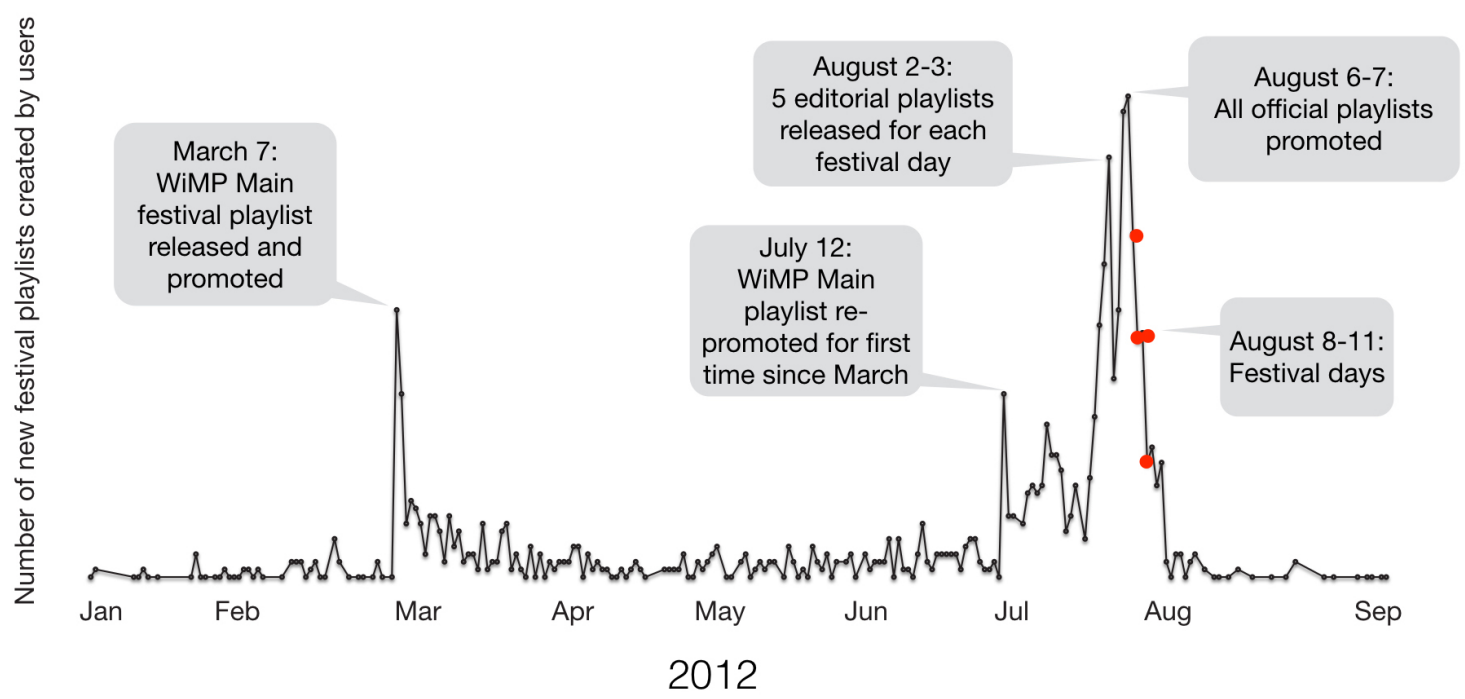

Figure 3: Timeline of creation date of new user-generated playlists containing "øya" in their names in 2012, and main promotional activities of the editorial festival lists by WiMP Music.

As figure 4 shows, the playlist streams spike on Wednesday one week before the festival starts, just as the playlists begin to be promoted in the top banners of the WiMP Music player, and this is followed by an even higher spike during the first two days of the festival. Streams from the main editorial lists then fall off sharply the week after the festival, while other festival-related streams (for example, streams by festival artists initiated from search, browsing, and user-generated playlists) show a more gradual decline. This suggests that editorial lists were used more for pre-event listening, while post-event listening practices arose more from listeners' individual choices than from editorial activity (see also Kjus and Danielsen). 
The peaks in streaming on the Friday and Saturday of the week following the festival (17-18 August) appear to reflect what I would call a "weekend echo," a common feature found in relation to other events in a large data set, such as big concerts or TV appearances, which often also produce a delayed peak during the following weekend (Maasø, "Surviving Streaming"). In general, Fridays and Saturdays are the top streaming days of the week (see also the peak on the Friday preceding the festival), and presumably many users play the music they have discovered during the week at weekend parties, peaking between 10:00 PM and midnight.

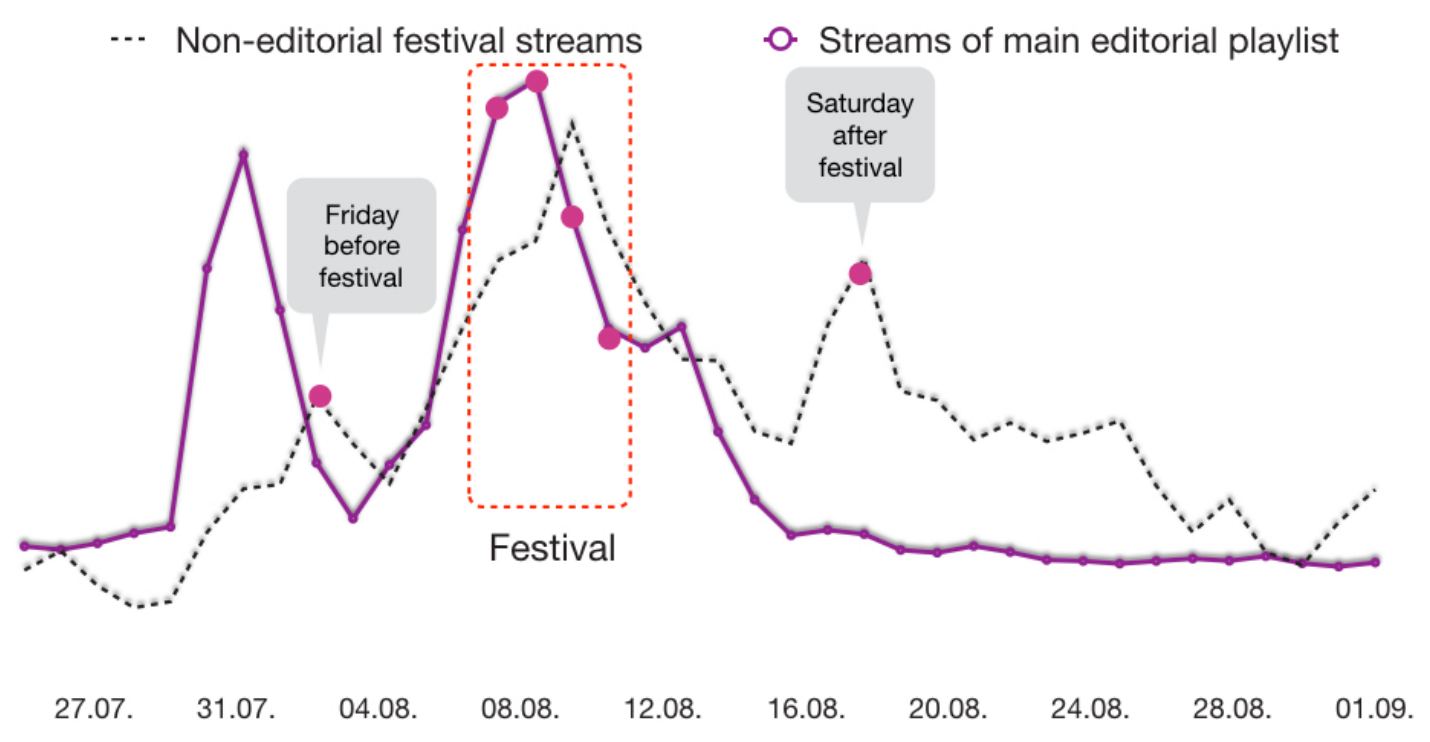

Festival streams from 26. July to 1. September 2012

Figure 4: Daily timeline of streams belonging to the main editorial festival lists, compared to all other streams by festival artists (that is, one of the seventy-nine artists performing at the festival) from 26 July to 1 September. Y-axis shows low to high number of streams. The two curves are normalized, for better comparison. 
In addition to this main editorial playlist, the second most important editorial elements related to the festival were the playlists for each of the four festival days, presenting tracks from the artists playing from Wednesday to Saturday. Lastly, several albums and individual artists playing at Øya were promoted in advance of, during, and after the festival. None of these other lists had anything close to the streaming numbers of the main playlist, which commanded 60 percent of all of the festival playlist streaming.

Streaming of each of the day lists peaked the day before the artists played (that is, Friday artists peaked on Thursday), except for the first festival day (Wednesday), which peaked on Monday — the first day in the festival week — when the list was promoted on the WiMP player. The playlist for the first festival day has the most streams of the four lists, and each of the subsequent days has fewer streams than the day prior. As will be discussed later, the patterns related to the "day lists" suggest a pre-listening mode that would apply to festivalgoers attending concerts on the next day, a mode of streaming use we also encountered in our focus-group interviews (Kjus and Danielsen). The same patterns were found over all four years.

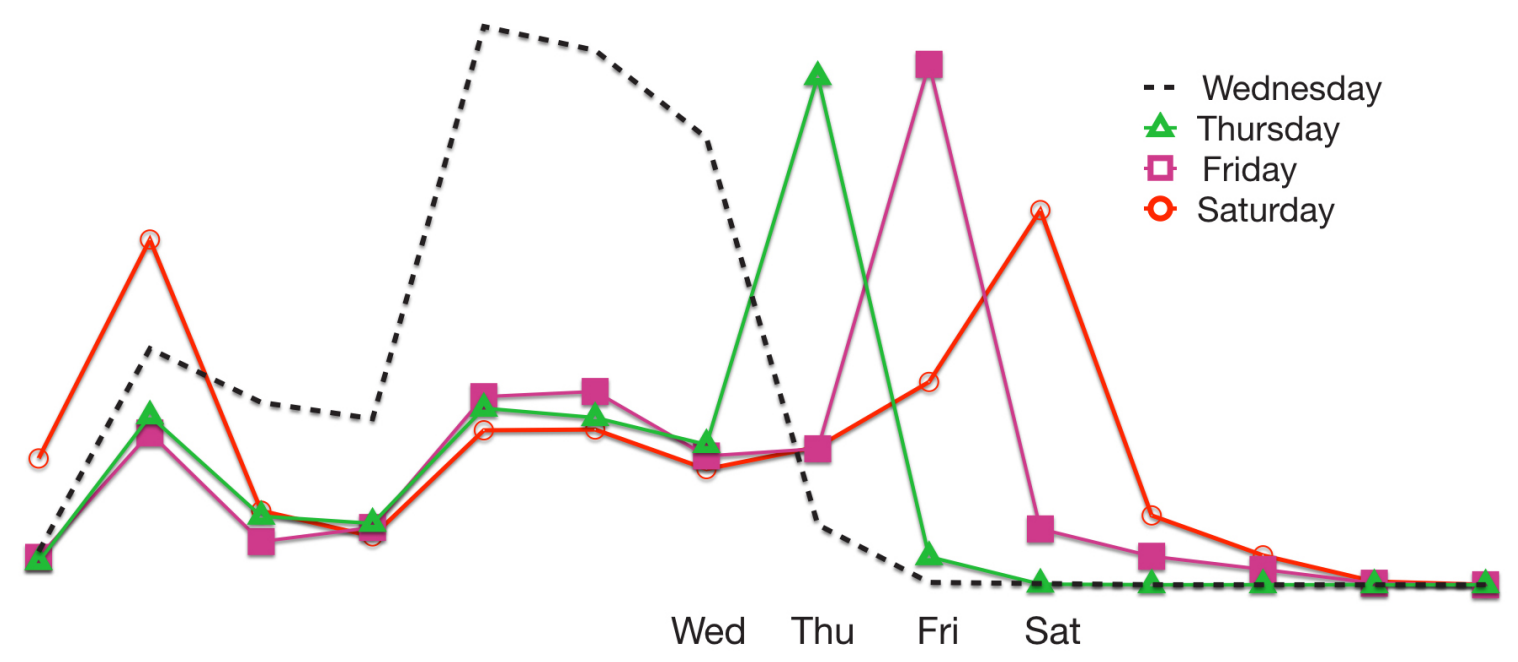

Timeline from 2. August to 15. August 2012 
Figure 5: Timeline of streams (low to high) from the four editorial lists dedicated to the artists performing on the four respective days of the Øya festival in 2012. The curves are not normalized and hence indicate the difference in streaming numbers between days.

\section{Event Search Patterns}

In addition to streaming and playlist creation, search queries performed in the WiMP Music players may indicate certain festival-related listening patterns. Of particular interest was finding out whether streaming users were searching for artists playing at the festival, and when searches occurred in relation to the timing of the artists' appearances.

Regarding top search terms in the days preceding the festival in 2012, a popular Norwegian hip-hop duo that performed there was among the top ten queries on eleven of the sixteen days leading up to the festival, and the only festival artist on this top ten list. During the three weeks following the festival, searches for three other festival artists appeared in the top ten search terms as well-all three gave live performances at the festival in 2012 and were among the most streamed artists during the festival week. During the four main festival days, these four acts and three other festival artists appeared in the lists of top ten search terms. In fact, three or four of the top ten terms on each of the festival days belonged to one of the Øya artists, while the rest of the top ten list was dominated by international artists found on the list throughout the year (such as Justin Bieber, Rihanna, Coldplay, Queen, and Bruce Springsteen), and by two Norwegian artists with top hits at the time who did not perform at Øya.

During the four festival days, thirty-five of the seventy-nine artists performing (44 percent) were among the top five hundred search queries in Norway as a whole. Search patterns thus showed that the festival artists clearly impacted the top search patterns during the festival week, as well as pre-event searches (of artists about to play) and post-event 
searches after successful concerts (with five of the seventy-nine festival artists being among the top ten search queries in WiMP Music in the days following their performance). ${ }^{10}$

\section{Discussion}

In what follows, discussion results from the festival study will be summarized and discussed. I will then go on to argue that the "festival effect" found in streaming patterns exemplifies a broader trend here labeled the eventization of listening, whereby outside events and happenings influence streaming patterns both on a micro level (the everyday choices individuals make when using music-streaming services) and on a macro level (event-related streams common to many users). The article ends with a discussion of how eventization may bring both centrifugal and centripetal forces to bear on music culture.

Summing up the findings for streams, playlists, and searches in relation to the Øya festival, streams during the seven-week extended festival period were up considerably per week in relation to the control weeks (an increase of 43 percent on average), suggesting that the live event impacts streaming for several weeks surrounding the event itself. Festival artists also enjoyed a large spike in streaming during the festival week for all four years studied. Festival streaming drops off fairly quickly after the live event, but remained 7 percent higher than the average three weeks before the festival.

The spike in festival streaming was especially high for users living in close proximity to the event, as opposed to users living an hour or two away, pointing to a likely overlap between the streaming and festival audiences, and perhaps also to the role of spatial and social proximity in the diffusion of music.

Editorial playlists were used more during pre-event listening leading up to the festival and showed a correspondingly sharper drop-off in post-event listening than the other festival streams did. Users seem to have abandoned editorial playlists in favor of other, more 
individual ways of listening to a select group of festival artists in their post-event practice (for example, making their own playlists, searching, listening to starred or "favorite" albums or artists, and so on), thus generating a "weekend echo effect" following the festival. The main editorial playlist for the festival was by far the most popular playlist and clearly impacted pre-event listening. The promotional activity of the streaming service prompted distinct spikes in both streaming and related user-generated activities, such as creating playlists based on the editorial lists. In sum, then, the Øya festival influenced pre-event, event, and postevent streaming patterns to a great extent for a large number of music listeners for the extended festival period.

It is clear that editorial decisions by the WiMP Music streaming service, such as the release of playlists, impacted streaming greatly. In the user interface of these various platforms, editorial content is front and center and greets users before they can access music from the catalogue in the WiMP player. Hence, the role of the editorial team in the streaming service resembles that of the gatekeepers of the traditional mass media. While it is possible to bypass the "gates" of this editorial team — and many users do — it is nevertheless evident from this study that many in fact followed the team's lead and took advantage of the content that it presented. The editorial influence was especially profound for pre-listening patterns, as users enjoyed easy access to editorial playlists with artists from the event, whether they were attending the event or not.

All subscribers to the streaming service in Norway see the same content in the WiMP music player as anyone else there (WiMP Music only differentiates its content by country). However, people living in Oslo also receive news about the festival through other media, much of which is local and regional. Likewise, they hear things about the festival from a variety of social networks in schools and workplaces, and from observing the physical 
changes in the city itself, including festival banners and logos, as well as the lines of people waiting for passes.

Based on studies of social contagion (Ugander et al.), structural diversity of social groups and endorsements from multiple and different sources are more important for the diffusion of information than the sheer size of networks alone (as was indicated by earlier social theory). Along these lines, then, a streaming user living in Oslo is more likely to get information about the festival from a multitude of online and offline sources than a user who lives further away, in turn explaining some of the streaming patterns found in this study.

The results, then, indicate a clear streaming impact with regard to artists associated with the Øya festival, and in our data many other events with a similarly profound impact were also identified, such as album releases, large stand-alone concerts by popular stars (Maasø, "Surviving Streaming”), appearances on primetime television with high ratings, deaths of popular artists, and the terror attacks in Oslo and Utøya on 22 July 2011 (Maasø and Toldnes).

The second main research question asked whether changes in streaming behavior related to this particular festival may point to more general user patterns surrounding large events, and it is to this issue that we next turn.

\section{Eventization of Listening}

Paddy Scannell (Scannell, "Big Brother”) draws a simple and useful distinction between two types of events: those that happen to us, and those that we make happen. The former he calls "happenings," and the latter, "events." Happenings have a fundamentally retrospective and unintended character - an earthquake, for example, or a plane crash. Events, unlike happenings, 
are known in advance. They are forward looking and looked forward to. For those who will participate in the event-that-is-to-come (performers and audiences), the occasion, from its very beginning, is invested with expectations. Thus, events have a fore-structure and, intimately linked to this, a structure of anticipation. (271)

All of the editorially curated content concerning festivals presented by WiMP Music is based on this event structure, building up the audience's anticipation and both encouraging and accommodating pre-event listening. This event structure also informs the other promoted content in the streaming service, such as the daily record releases and other music "news." Even unplanned happenings sometimes turn into planned editorial events, as when an artist dies and an editorial playlist is dedicated to him or her, or when WiMP Music, a few days after the terror attacks in Norway, released the playlist titled "Songs of Solace," curated by the public service broadcaster in Norway (Maasø and Toldnes).

It is well established that much media content and usage are dominated by what is thought to be news or newsworthy, whether happenings, independent events, or "media events." It is also clear that people query Twitter or search engines regarding breaking events or events that occupy conversations around the water cooler or dominate the mass media. Trending search patterns are occasionally reported by search engines, such as the search patterns in Google after the 9/11 terror attacks (Wiggins) or via the annual "Top 10 searches" reported by Yahoo since 2001. ${ }^{11}$ In a forthcoming article, Tarleton Gillespie (3) discusses the impact of trending algorithms in social media, which use "a combination of metrics to identify particular content or topics generating the most activity, at a particular moment, and among a particular group of users": "Unlike search," writes Gillespie, "trending algorithms promise a glimpse into what may be popular or of interest to others, a barometer of 'what's going on"” (8). While search patterns do not necessarily become observable to other users in the same way that trending hashtags or top charts are, searches can still be trending and 
become indexes of the popular, as shown by the music-streaming services above. Likewise, search trends may influence trending algorithms, in Gillespie's sense, as they become the basis for autocomplete suggestions. Searches also likely contribute to the ranking algorithms that generate top charts and suggested top hits that appear for different artists in the streaming services.

Sometimes spikes in both music streaming and searches are also reported in the media as news, such as the sudden interest in the British rock band Badfinger's song "Baby Blue" from 1972 after the finale of Breaking Bad in September 2013, or the recurrent streaming of Aerosmith's song “Don't Want to Miss a Thing” (featured in the movie Armageddon) in relation to any events featuring comets and meteors. More recently, the release of the complete Beatles catalog on several streaming services on 24 December 2015 broke records for the simultaneous streaming of a single artist in Spotify (see Hernandez; Van Buskirk, “Comet Landing"; Van Buskirk, "Beatles”; and Maasø and Toldnes for further examples).

I propose that these demonstrations of event-based listening trends are coming to represent a trend in and of themselves in streaming culture - one that is leading to what might be called the eventization of listening (a term adapted from the German term Eventisierung by Ronald Hitzler). While Gillespie focuses on algorithms and social media, I believe the "trending" phenomenon he describes to be very much akin to eventization; some of the effects are clearly enhanced (if not produced) by algorithms, and others by the editorial processes in music-streaming services, by festival curators, or by current events in society and media.

Of course, major events have prompted listening activity throughout popular music history, from song slides and sheet music in the silent-film era (Abel and Altman), to popular songs in early sound films, to decades upon decades of Top 40 and hit-based radio formats, to Elton John's televised performance of the song "England's Rose" at the funeral of Lady 
Diana. Yet it is only with the popular embrace of music streaming — and so many users sharing instant access to the same sprawling catalog of music — that it has become possible for big events to immediately grab the attention of a huge group of streamers at once and in turn introduce eventization as a regular and recurring phenomenon.

Likewise, it is only in music culture since the turn of the millennium that so many users have started to acquire large personal archives of digital files. Portable digital music players have allowed users to carry with them entire personal collections, through all of the events, activities, moods, and interactions that constitute daily life (Bull; Nag). With so much music in their pockets, users can impact their daily experiences by defining or at least ornamenting their own personal space and time: "Listening to chosen music enables [...] iPod users to focus in on themselves," using their own collections to reframe their experiences and transform the world into something "intimate, known and possessed," observes Michael Bull (349).

While there is a dearth of large, quantitative studies of the ways in which people used to listen on iPods and computers, as well as the actual size of their personal archives, there is a 2006 project involving data from 5,600 iPod users (Lamere) that appears to indicate only a modest possibility for event-based listening in comparison to the current situation. Among those iPod listeners, the average user had 3,542 songs on an iPod but had played only 800 of them, indicating that event-based listening was limited, and that it would hardly have been sufficient to, for example, listen to all of the artists performing at an upcoming festival. ${ }^{12}$ Hence, in music culture before streaming (radio aside), one was more likely listening to the music one already liked and had in one's collection, regardless of what was happening in the world beyond. While events might have motivated users when purchasing or downloading new music, the threshold for event-based listening is much lower with streaming now, because one does not need to purchase individual songs or albums, or make time and room to 
download a local copy on a device. The possibilities around using music to control one's mood or accommodate any given situation, context, or event are thus increased exponentially through YouTube and music-streaming services such as WiMP Music and Spotify.

The low threshold for sampling and exploring music on streaming services, at no extra cost, makes it virtually risk free to check out editorial content related to an event. If one does not like it, one simply moves on, freed from the commitment of a purchase or download, as was implied with previous music media.

The instant availability of a large music catalogue is hence the most commonly cited streaming advantage, by informants across the aforementioned focus-group interviews; many of these people also described a wide variety of browsing and searching strategies (see more below) when looking for music and working with playlists (Hagen). Music available "on a whim" thus appears to be a precondition for the possibility of eventization to take place and is arguably one of the fundamental affordances of interactive music streaming as such.

\section{Event-Based Listening on the Micro and Macro Levels}

To further explore the impact of events on streaming, it may be useful to distinguish between the micro level (individual) and the macro level (collective). Among the focus groups engaged for this research project, "browsing," listening on a whim, or sampling a track triggered by various associations were all common ways of listening, as illustrated by the following typical statements, translated from Norwegian by the author:

Then it's the "on-a-whim" method; I hear about a band, or something, and check the streaming service, and listen to it. (Man, 29) 
I check out music I've heard about, or things I want to see live. I often use streaming as a kind of "exploring tool." (Woman, 25)

I like to see what others are playing on Spotify or Facebook, and check out what others are listening to. (Man, 30)

The most common contexts in which such statements occur in the focus-group discussions are the desire for immediacy, curiosity, interest in other people's tastes, the ease of use of streaming services, and the ways of dealing with the abundance of the streaming catalog. The use of outside events and happenings to inspire and reconfigure one's listening patterns may thus be interpreted as a coopting of one of radio's traditional functions - that of delivering us from the "burden of choice" (Frith, "Music," 42).

Sometimes individual "micro-level" streams run together, then, into a river of similar choices that begins to suggest truly collective behavior. It is as though many private associations turn in to fewer common connotations, based on coincident events or happenings, such as the Øya festival or the release of the Beatles catalogue. Macro-level patterns may or may not imply communal or ritual gestures, in the tradition of media events (as described by Dayan and Katz). Ritualized, shared responses are clearly relevant to situations such as the streaming after the terror attacks in 2011 (Maasø and Toldnes). Other sorts of events provide a shared basis for conversation as well, as was the case both in social media and around the proverbial water cooler after the passing of David Bowie in January 2016.

As Stowe argues, broadcasting and records have functioned differently in acting to organize individuals into audiences. While radio created mass audiences for musical forms, records allowed people to cultivate more individual tastes in private (see also Straw). Streaming, hence, accommodates both the public and the private. For the given listener, 
private listening may be considered more important, as appeared to be the case with the focus groups (Hagen and Lüders), and as is clear from the fact that only 8 percent of the user-

generated playlists on WiMP Music are shared with other users. Yet the possibility of private listening becoming a collective practice at the macro level is arguably much more likely with regard to streaming than it was for an earlier mediated music culture, because of the instant availability of the music. With network effects further impacting diffusion at the macro level through one's online and offline social networks (Granovetter, "Weak Ties"; Granovetter, "Revisited"; McPherson, Smith-Lovin, and Cook; Watts; Hampton et al.; Ugander et al.), music that is heavily streamed and shared spreads quickly and reaches more listeners over a shorter time than was the case previously (apart from broadcasting). ${ }^{13}$

It is also likely that once a particular song reaches a certain streaming threshold, seeing and hearing what other users are streaming also gives certain songs and artists cumulative advantages that are similar to the Matthew effect (Salganik, Dodds, and Watts; Salganik and Watts). So-called event-based (or event-driven) computer programming (Lee), through which the flow of the program is determined by things such as user actions, may itself contribute to these cumulative advantages - for example, when ranking algorithms advance songs with many streams on a "top list" or suggest certain artists or songs in the autocomplete field based on often-performed searches. Algorithms and social mechanisms within streaming media may thus work in tandem to transform micro events into macro events.

\section{Conclusion: The Centrifugal and Centripetal Forces of Eventization}

The study of streaming encompasses the ways in which outside events can influence listening patterns not only on an individual level or in small groups but also for thousands or even millions of listeners. This article has explored the ways in which a large music festival 
impacts patterns of streaming. In more general terms, it has also addressed the ways in which events planned by a label, a festival, or an editorial team at a streaming service can become "top of mind" for many users and inform the choices being made by other people streaming music at the same time.

This article argues that the "festival effect" found in streaming patterns exemplifies a broader trend here labeled the eventization of listening. This eventization may bring both centrifugal and centripetal forces to bear on music culture. On the one hand, it may bring attention to local events or artists that are not part of the global mainstream, as is the case with the Øya festival for audiences in Norway, and especially in Oslo. On the other hand, it may promote or validate already trending events and artists already dominating global music culture, as when a superstar releases a new album, or dies, or both.

Given the ever-increasing catalogues available via music-streaming services, the exploitation of events may prove to be an effective way of eliciting attention for particular acts. One question worth addressing further, then, would involve the long-term consequences of "super events" and "blockbusters" on music culture in general. Will eventization move music toward more collective listening practices and musical homophily? Will revenue generation in the "long tail" of digital media (Anderson), with repeated listening to music distributed over time, suffer from the way that mega events attract attention and focus streaming of events here-and-now? And will eventization, in combination with social network effects and trending algorithms, give superstars cumulative advantages that lead to further concentration? Such questions are only the first to emerge from the conclusions of this study. 


\section{Acknowledgments}

This article was produced under the auspices of the Clouds and Concerts research project at the University of Oslo, funded by the Research Council of Norway (grant number 205265). Many people were involved in the quantitative data analysis that provided the basis for the research. Research assistants Ola Løvholm and Xin Jian did the main work, in collaboration with the author. In 2010 Johannes Bjelland and Pål Roe Sundsøy at the Telenor Group set up the database, along with Kenth Engø-Monsen; they also mapped streaming to postal codes, performed the initial analysis, and helped with troubleshooting in subsequent years. Beathe Due (project leader at Telenor) was instrumental in initiating the 2010 study, as well as conducting the focus-group interviews together with the author, Anne Danielsen, and later Yngvar Kjus. Finally, research assistants Hanne Tråsdal and Marc Casanovas took part in some of the initial quantitative analyses. Gratitude goes to all of them.

\section{Notes}

\footnotetext{
${ }^{1}$ Services like Pandora or iTunes radio do not let users search, play, or skip individual songs. So-called "Internet radio" or non-interactive streaming must thus be distinguished from interactive streaming or on-demand streaming, as is discussed here.

${ }^{2}$ A browser version of the service is available at WiMP Music or TIDAL. See also screenshots of the service on various platforms at WiMP (WIMP Mediaroom).

${ }^{3}$ It must be noted that placement in playlists cannot be bought, and the editorial team was very determined to cultivate an ethos of independence and authenticity regarding the music it recommends, but the service also acknowledged its shared interests with labels, artists, and festivals. Interview by author with Sveinung Rindal, Head of Editorial Campaigns at WiMP Music, March 20, 2011. See also Kjus.

${ }^{4}$ Interviews by author with Birgitte Mandelid, Marketing Manager of the Øya festival, 16 June and 14 September 2010.
} 
${ }^{5}$ Official user data reported by WiMP Music in public stock exchange announcements listed 100,000 users by the end of $2010,300,000$ by the end of $2011,350,000$ by May 2012, and 520,000 by the end of 2013 .

${ }^{6}$ Kjus and Danielsen (2014), however, draw upon unpublished streaming data from the present study in their work.

${ }^{7}$ Further information may be found at Wikipedia (Wikipedia) or the official festival site for the Lowlands festival (Lowlands).

${ }^{8}$ Sample scripts and further details are available on GitHub (GitHub). For most of the analyses presented here, only users with more than one hundred streams over nine weeks were included, in order to avoid users who were new to streaming and to privilege those who streamed music on a daily or weekly basis.

${ }^{9}$ Listening patterns of what one might call "festival listeners"- that is, the 20 percent of users in 2012 who had the highest percentage of their streams involving festival artists during the four festival days - were also compared with a random sample of the 20 percent of users who had no streams by festival artists ("non-festival listeners"). This analysis showed that festival listeners, on average, had 25 percent more streams than non-festival listeners. Of "super fans" within certain genres (that is, the top 10 percent of listeners with the highest ratio of streams of a particular genre), there was a particularly high correlation between festival listeners and fans of alternative/indie (25 percent of festival listeners were super fans of alternative), whereas only 4 percent of festival listeners were super fans of pop. On average, WiMP users were streaming 48 percent pop tracks and only 5 percent alternative/indie tracks at this time (Maasø, "Clouds and Concerts").

${ }^{10}$ An analysis of search queries during the festival week in 2011 shows similar patterns, with twenty-four of the top one hundred search queries belonging to one of the eighty artists playing at the festival. 
${ }^{11}$ In 2006, Google added Google trends, with which one can track a search term's use relative to total search volume across various regions of the world, and in various languages, over time (Google Trends). The annual top ten searches released by Google are based on year-versus-year search trends - in other words, how popular a search was this year versus last—rather than raw frequency. Also, see Yahoo! annual top trends (Chan).

${ }^{12}$ Lamere did not report on what period of time these users listened to those 800 songs, however. Likewise, the study's data came from a site where users could upload their own iTunes usage information, and it was hence likely skewed (for example, by age and gender). ${ }^{13}$ See Maasø and Toldnes for a discussion of network effects and the way in which certain "songs of solace" after the 22/7 terror attacks in Norway spread through a combination of streaming and broadcasting. 


\section{Works Cited}

Abel, Richard, and Rick R. Altman, eds. The Sounds of Early Cinema. Bloomington: Indiana UP, 2001. Print.

Anderson, Chris. The Long Tail: How Endless Choice Is Creating Unlimited Demand. New York: Random House, 2007. Print.

Baccigalupo, Claudio, and Enric Plaza. "Mining Music Social Networks for Automating Social Music Services.” Workshop Notes of the ECML/PKDD 2007 Workshop on Web Mining 2 (2007): 123-34. Web.

Bauman, Zygmunt. Liquid Modernity. Cambridge: Polity Press, 2013. Print.

Baym, Nancy K., and Andrew Ledbetter. “Tunes That Bind? Predicting Friendship Strength in a Music-Based Social Network." Information, Communication \& Society 12.3 (2009): 408-27. Web.

Begg, Robbie. "Culturing Commitment: Serious Leisure and the Folk Festival Experience." Festival Places: Revitalising Rural Australia. Eds. Chris Gibson and John Connell. Sydney: Channel View Publications, 2011. 248-64. Print.

Brennan, Matt, and Emma Webster. "Why Concert Promoters Matter.” Scottish Music Review 2.1 (2011): 1-25. Web. 
Buldu, Javier M., Pedro Cano, Markus Koppenberger, Juan A. Almendral, and Stefano Boccaletti. “The Complex Network of Musical Tastes.” New Journal of Physics 9 (2007): 1-16. Web.

Bull, Michael. "No Dead Air! The iPod and the Culture of Mobile Listening.” Leisure Studies 24.4 (2005): 343-55. Web.

Burkart, Patrick. "Trends in Digital Music Archiving.” The Information Society 24.4 (2008): 246-50. Web.

Chan, Vera H.-C. “Top 10 Searches of 2014.” Yahoo! Tech. Yahoo!, 13 Jan. 2015. Web. 9 July 2016. 〈https://www.yahoo.com/tech/top-10-searches-of-2014c1417565661893.html〉.

Couldry, Nick, Andreas Hepp, and Friedrich Krotz. Media Events in a Global Age. London: Routledge, 2010. Print.

Dayan, Daniel, and Elihu Katz. Media Events: The Live Broadcasting of History. Cambridge: Harvard UP, 1992. Print.

DeNora, Tia. Music in Everyday Life. Cambridge: Cambridge UP, 2000. Print.

Duffy, Michelle. "Lines of Drift: Festival Participation and Performing a Sense of Place." Popular Music 19.1 (2000): 51-64. Web.

Elberse, Anita. Blockbusters: Hit-Making, Risk-Taking, and the Big Business of Entertainment. New York: Macmillan, 2013. Kindle file.

Florida, Richard. The Rise of the Creative Class: And How It's Transforming Work, Leisure, Community and Everyday Life. New York: Basic Books, 2002. Print.

Fonarow, Wendy. Empire of Dirt: The Aesthetics and Rituals of British Indie Music. Middletown: Wesleyan UP, 2006. Print.

Frith, Simon. "Live Music Matters." Scottish Music Review 1.1 (2007): 1-17. Web. ---. "Music and Everyday Life.” Critical Quarterly 44.1 (2002): 35-48. Web. 
---. "The Popular Music Industry.” The Cambridge Companion to Pop and Rock. Eds. Simon Frith, Will Straw, and John Street. Cambridge: Cambridge UP, 2011. 26-52. Print.

Getz, Donald. Event Management and Event Tourism. 2nd ed. New York: Cognizant, 2005. Print.

---. Event Studies: Theory, Research and Policy for Planned Events. Oxford: Elsevier, 2007. Print.

---. “Event Tourism: Definition, Evolution, and Research.” Tourism Management 29 (2008): 403-28. Web.

Gibson, Chris, and John Connell. Music Festivals and Regional Development in Australia. Farnham: Ashgate, 2012. Print.

Gibson, James J. The Ecological Approach to Visual Perception. Hillsdale: Lawrence Erlbaum Associates, 1986. Print.

Gillespie, Tarleton (forthcoming). “\#Trendingistrending: When Algorithms Become Culture." Algorithmic Cultures: Essays on Meaning, Performance, and New Technologies. Eds. Robert Seyfert and Jonathan Roberge. London: Routledge, forthcoming. Web. 23 June 2016. «https://socialmediacollective.org/2016/02/ 01/trendingistrending-when-algorithms-become-culture/>.

Gillespie, Tarleton, Pablo J. Boczkowski, and Kirsten A. Foot, eds. Media Technologies: Essays on Communication, Materiality, and Society. Cambridge: MIT Press, 2013. Print.

GitHub. “Clouds and Concerts”. GitHub. GitHub, Inc., n.d. Web. 9 July 2016. 〈https://github.com/CloudsAndConcerts〉.

Google Trends. Google, n.d. Web. 9 July 2016. «ttps://www.google.com/ trends/>. 
Granovetter, Mark S. “The Strength of Weak Ties.” American Journal of Sociology 78.6 (1973): 1360-80. Web.

---. “The Strength of Weak Ties: A Network Theory Revisited.” Sociological Theory 1 (1983): 201-33. Web.

Hagen, Anja N. (2015). Using Music Streaming Services: Practices, Experiences and the Lifeworld of Musicking. Diss. University of Oslo, 2015. Print.

Hagen, Anja N., and Marika Lüders. "Social Streaming? Navigating Music as Personal and Social." Using Music Streaming Services: Practices, Experiences and the Lifeworld of Musicking. Anja N. Hagen. Diss. University of Oslo, 2015. Print.

Hampton, Keith, Lauren S. Goulet, Cameron Marlow, and Lee Rainie. "Why Most Facebook Users Get More than They Give.” Pew Internet and American Life Project, 2012. Web. 6 July 2016. «http://www.pewinternet.org/files/oldmedia//Files/Reports/2012/PIP_Facebook\%20users_2.3.12.pdf〉.

Häußermann, Hartmut, and Walter Siebel. (1993). Festivalisierung der Stadtpolitik: Stadtentwicklung Durch Große Projekte. Leviathan, Sonderheft 13. Opladen: Westdeutscher Verlag, 1993. Print.

Hernandez, Brian A. ““Breaking Bad' Finale Increases Spotify Streams for 'Baby Blue’ by 9,000\%.” Mashable. N.p., 1 Oct. 2013. Web. 10 Oct. 2015. 〈http://mashable.com/2013/09/30/breaking-bad-finale-baby-bluespotify/?utm_cid=Mash-Prod-RSS-Feedburner-All-Partial\#LsWsQZzuemqf`.

Hesmondhalgh, David. Why Music Matters. Oxford: Wiley-Blackwell, 2013. Print.

Hitzler, Ronald. Eventisierung: Drei Fallstudien zum Marketingstrategischen Massenspass. Wiesbaden: VS Verlag für Sozialwissenschaften, 2011. Kindle file.

Hochschild, Arlie R. (1979). “Emotion Work, Feeling Rules, and Social Structure.” American Journal of Sociology 85.3 (1979): 551-75. Web. 
Holt, Fabian. "The Economy of Live Music in the Digital Age." European Journal of Cultural Studies 13.2 (2010): 243-61. Web.

Ingham, Tim. "Why Norway and the UK Produce the World's Most Valuable Music Fans." Music Business Worldwide. MBW, 10 Sep. 2015. Web. 20 Sep. 2015. 〈http://www.musicbusinessworldwide.com/norway-uk-produce-worlds-valuablemusic-fans/>.

Jones, Steve. "Music and the Internet." Popular Music 19.2 (2000): 217-30. Web.

---. "Music That Moves: Popular Music, Distribution and Network Technologies." Cultural Studies 16.2 (2002): 213-32. Web.

Karlsen, Faltin, Vilde S. Sundet, Trine Syvertsen, and Espen Ytreberg. "Media Participation: Opportunities and How They Are Used." Public Participation in Multi-Platform Media, ESF SCSS Exploratory Workshop, Lysebu, Oslo, 1-3 Sep. 2006. Paper presentation.

Katz, Mark. Capturing Sound: How Technology Has Changed Music. Berkeley: U of California P, 2004. Print.

Kjus, Yngvar. "Reclaiming the Music: The Power of Local and Physical Music Distribution in the Age of Global Online Services." New Media and Society. Published online before print (2015). Web. 6 Jul. 2016. 〈http://nms.sagepub.com/content/early/2015/04/07/1461444815580414〉.

Kjus, Yngvar, and Anne Danielsen. "Live Islands in the Seas of Recordings: The Music Experience of Visitors at the Øya Festival.” Popular Music and Society 37.5 (2014): 660-79. Web.

Lamere, Paul. “What's on Your iPod?” Duke Listens! N.p., 22 May 2006. Web. 7 Jul. 2016. 〈http://static.echonest.com/DukeListens/what_s_on_your_ipod.html〉. 
Lee, Conrad, and Pádraig Cunningham. “The Geographic Flow of Music.” arXiv. Cornell University Library, 2012. Web. 7 Jul. 2016. 〈http://arxiv.org/pdf/1204.2677v1.pdf〉. Lee, Kent D. "Event-Driven Programming.” Python Programming Fundamental. London: Springer, 2011. 149-65. Print.

Lowlands. Lowlands festival, n. d. Web. 26 Nov. 2015. 〈http://lowlands.nl/en/〉.

Maasø, Arnt. "Clouds and Concerts: WiMP and Consumer Behaviour.” By:Larm, Oslo. 1518 Feb. 2012. Web. 7 Jul. 2016. 〈http://www.hf.uio.no/ imv/forskning/prosjekter/skyogscene/publikasjoner/cloudsconcerts_bylarm_160212.p df .

---. "Surviving Streaming: How Insight into Listening Patterns and the Streaming Model Provides Maps for the Future.” Berlin Music Week, Berlin. 3-7 Sep. 2014. Web. 7 Jul. 2016. 〈http://www.hf.uio.no/imv/english/research/projects/ cloudsandconcerts/publications/surviving_streaming_berlin_maaso_050914.pdf〉. Maasø, Arnt, and Ragnhild Toldnes. [Songs of Solace] "Mitt lille land: Sørgemusikk og sosiale strømmer.” Musikk etter 22. Juli. Eds. Jan S. Knudsen, Marie S. Skånland, and Gro Trondalen. Oslo: Norges Musikkhøgskole, 2014. 25-48. Print.

Mackellar, Joanne. "Dabblers, Fans and Fanatics: Exploring Behavioural Segmentation at a Special-Interest Event.” Journal of Vacation Marketing 15.1 (2009): 5-24. Web. McCourt, Tom, and Patrick Burkart. "When Creators, Corporations and Consumers Collide: Napster and the Development of On-Line Music Distribution." Media, Culture \& Society 25.3 (2003): 333-50. Web.

McPherson, Miller, Lynn Smith-Lovin, and James M. Cook. "Birds of a Feather: Homophily in Social Networks.” Annual Review of Sociology 27 (2001): 415-44. Web. 
Mulligan, Mark (2014). “The Death of the Long Tail.” Music Industry Blog. N.p., 4 Mar.

2014. Web. 7 Jul. 2016. 〈http://musicindustryblog.wordpress.com/2014/

03/04/the-death-of-the-long-tail/s.

Nag, Wenche. "Musikkbruk og forretningsmodeller i en delingskultur." Norsk Medietidsskrift 17.1 (2010): 46-66. Web.

North, Adrian C., David J. Hargreaves, and Jon J. Hargreaves. "Uses of Music in Everyday Life." Music Perception 22.1 (2004): 41-77. Web.

Page, Will. "Adventures in the Lowlands: Best Practice for Spotify, Social Media and Festivals.” Spotify, 22 Oct. 2014. Web. 7 Nov. 2015.

〈https://spotifyinsights.files.wordpress.com/2014/10/adventures-in-the-lowlands.pdf〉.

Roberts, Daniel. “Tidal Subscriptions.” Yahoo Tech, 1 Jul. 2016. Web. 3 Jul. 2016.

$<$ http://finance.yahoo.com/news/jay-z-music-streaming-service-tidal-appleacquisition-rumors-kanye-beyonce-madonna155621628.html?soc_src=mail\&soc_trk $=$ ma $>$

Rowley, Jennifer, and Catrin Williams. "The Impact of Brand Sponsorship of Music Festivals.” Marketing Intelligence and Planning 26.7 (2008): 781-92. Web.

Salganik, Matthew J., Peter S. Dodds, and Duncan J. Watts. “Experimental Study of Inequality and Unpredictability in an Artificial Cultural Market.” Science 311.5762 (2006): 854-56. Web.

Salganik, Matthew J., and Duncan J. Watts. "Leading the Herd Astray: An Experimental Study of Self-Fulfilling Prophecies in an Artificial Cultural Market.” Social Psychology Quarterly 71.4 (2008): 338-55. Web.

Scannell, Paddy. "Big Brother as a Television Event." Television and New Media 3.3 (2002): 271-82. Web.

---. "Media Events: A Review Essay.” Media, Culture and Society 17 (1995): 151-57. Web. 
Schindler, Alexander, Rudolf Mayer, and Andreas Rauber (2012). "Facilitating Comprehensive Benchmarking Experiments on the Million Song Dataset.” 13th International Society for Music Information Retrieval Conference, Porto, 8-12 Oct. 2012. Web. 7 July 2016. 〈ismir2012.ismir.net/event/papers/469-ismir-2012.pdf〉. Schlitter, Nico, and Tanja Falkowski (2009). "Mining the Dynamics of Music Preferences from a Social Networking Site.” 2009 International Conference on Advances in Social Network Analysis and Mining, Athens. Web. 7 Jul. 2016. 〈http://www.nicoschlitter.de/downloads/SchlitterFalkowski_ASONAM2009.pdf〉.

Skinner, Bruce E., and Vladimir Rukavina. Event Sponsorship. Chichester: John Wiley and Sons, 2002. Print.

Sloboda, John A., and Susan A. O’Neill (2001). "Emotions in Everyday Listening to Music.” Music and Emotion: Theory and Research. Eds. Patrik N. Juslin and John A. Sloboda. Oxford: Oxford UP, 2001. 415-29. Print.

Sterne, Jonathan. "The Mp3 as Cultural Artifact.” New Media and Society 8.5 (2006): 82542. Web.

Stowe, David W. Swing Changes: Big-Band Jazz in New Deal America. Cambridge: Harvard UP, 1994. Print.

Straw, Will. "Music and Material Culture.” The Cultural Study of Music. Eds. Martin Clayton, Trevor Herbert, and Richard Middleton. London: Routledge, 2012. 227-326. Print.

Strutz, Erik N. All the Music, All the Time: En Sammenlignende Analyse av Streamingtjenestene Spotify og Wimp. Master's thesis. University of Oslo, 2010. Web. Sundet, Vilde S. Making Sense of Mobile Media: Institutional Working Notions, Strategies and Actions in Convergent Media Markets. Diss. University of Oslo, 2012. Print. TIDAL. Aspiro, n.d. Web. 8 July 2016. «http://listen.tidal.com/〉. 
Tjora, Aksel, ed. Festival! Mellom rølp, kultur og noering. Oslo: Cappelen Damm Akademisk, 2013. Print.

TNS Gallup. “InterBuss Q2 2015. Norges største undersøkelse om Internettvaner.” Oslo: TNS Gallup, 2015. Report. Aug. 2015.

TNS Gallup. “InterBuss Q2 2016. Norges største undersøkelse om Internettvaner.” Oslo: TNS Gallup, 2015. Report. 9 July 2016.

Ugander, John, Lars Backstrom, Cameron Marlow, and Jon Kleinberg. "Structural Diversity in Social Contagion.” Proceedings of the National Academy of Sciences 109.16 (2012): 5962-66. Web.

Van Buskirk, Eliot. "Comet Landing Boosts Aerosmith Listening." Spotify Insights. Spotify, 21 Nov. 2014. Web. 3 Nov. 2015. «https://insights.spotify.com/no/ 2014/11/21/aerosmith-rosetta-comet/>.

---. "Meet the Beatles Data.” Spotify Insights. Spotify, 22 Jan. 2016. Web. 26 Jan. 2016. 〈https://insights.spotify.com/int/2016/01/22/meet-the-beatles-data/〉.

Waterman, Stanley. "Carnival for Élites? The Cultural Politics of Arts Festivals." Progress in Human Geography 22.1 (1998): 54-74. Web.

Watts, Duncan J. Six Degrees: The Science of a Connected Age. New York: W. W. Norton, 2003. Print.

Wiggins, Richard W. (2001). "The Effects of September 11 on the Leading Search Engine.” First Monday 6.10 (2001). Web. 〈http://dx.doi.org/10.5210/ fm.v6i10.890>.

Wikipedia. "Lowlands (Festival)." Wikipedia: The Free Encyclopedia. Wikimedia Foundation, Inc., 4 June 2016. Web. 9 July 2016. 〈https://en.wikipedia.org/ wiki/Lowlands_(festival)〉. 
WiMP. "Multimedia.” WiMP Mediaroom. Aspiro Music, n.d. Web. 28 Oct. 2015. 〈http://wimpmusic.en.mediaroom.com/index.php?s=20291 .

WiMP Music. Aspiro Music, n.d. Web. 9 July 2016. 〈http://play.wimpmusic.com/〉.

Yeoman, Ian, Martin Robinson, Jane Ali-Knight, Siobhan Drummond, and Una McMahonBeattie. Festival and Events Management: An International Arts and Culture Perspective. London: Routledge, 2004. Kindle file.

Ytreberg, Espen. “Towards a Historical Understanding of the Media Event.” Media Culture \& Society. Published online before print (2016). Web. 9 Jul. 2016.

Zittrain, Jonathan. The Future of the Internet: And How to Stop It. London: Allen Lane, 2008. Print. 